M. A. BERLiner, * S. P. A. DUBANT, T. MAKOWSKI, K. NG, B. SitTER, C. WAGER,

Use of an Iridium-Catalyzed Redox-Neutral Alcohol-Amine Coupling on Kilogram Scale for the Synthesis of a

\section{Synthesis of PF-03463275}

Key words

PF-03463274

glycine transporter type 1 inhibitors

iridium-catalyzed hydrogen borrowing<smiles>OC[C@@H]1C[C@H]2CN(Cc3ccccc3)C[C@H]12</smiles>

A

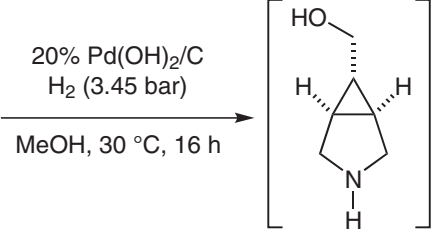

B aq $\mathrm{HCHO}$ (1.2 equiv) $\mathrm{H}_{2}$ (3.45 bar)

$\mathrm{MeOH}, 30^{\circ} \mathrm{C}, 8 \mathrm{~h}$ $90 \%(13.5 \mathrm{~mol}$ scale $)$<smiles>CN1C[C@@H]2[C@H](CO)[C@@H]2C1</smiles>

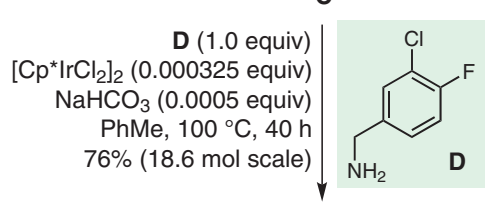

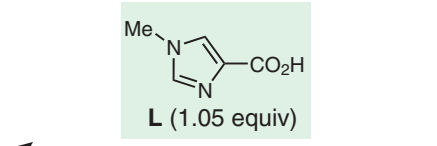

L (1.05 equiv)

T3P (1.25 equiv) $\mathrm{EtNMe}_{2}$ (4.25 equiv) $\mathrm{CH}_{2} \mathrm{Cl}_{2}, 5-25^{\circ} \mathrm{C}$ then $\mathrm{Na}_{2} \mathrm{CO}_{3}$ (4.2 equiv) in $\mathrm{H}_{2} \mathrm{O}$ then Darco KBB (50 wt\%) $87 \%$ (13.3 mol scale)

$\mathrm{T} 3 \mathrm{P}=n$-propanephosphonic acid cyclic anhydride<smiles>C[C@H]1C[C@H]2[C@@H](CNCc3ccc(F)c(Cl)c3)CN(C)C[C@@H]12</smiles>

Schematic representation of metal-catalyzed hydrogen borrowing:

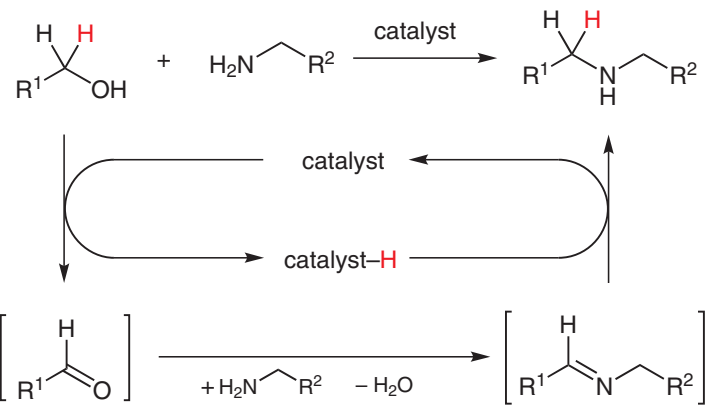

Significance: PF-03463275 is a glycine transporter type 1 (GlyT1) inhibitor that has potential for the treatment of schizophrenia. The synthesis depicted features the first kilogram-scale application of iridium-catalyzed hydrogen borrowing to achieve the operational equivalent of reductive amination in the union of $\mathbf{C}$ and $\mathbf{D}$ to give $\mathbf{E}$. The only byproduct of the reaction is water.

synfacts Contributors: Philip Kocienski

Synfacts 2011, 12, 1267-1267 Published online: 18.11.2011 Dol: 10.1055/s-0031-1289315; Reg-No.: K05711SF
Comment: An extensive optimization study achieved a S/C of $\geq 2000$ (i.e. lower than 0.05 mol\% of catalyst), but the reaction tended to stall thereby requiring a second charge of catalyst. After this work was complete the authors discovered that water and a tertiary amine are essential for high catalyst activity resulting in high rates and complete conversion on a single charge. 